\title{
CCL2/CCR2-Dependent Recruitment of Th17 Cells but Not Tc17 Cells to the Lung in a Murine Asthma Model
}

\author{
Aili Wang Zhengyun Wang Yong Cao Sheng Cheng Huilong Chen \\ Hansvin Bunjhoo Jungang Xie Congyi Wang Yongjian Xu Weining Xiong \\ Department of Respiratory and Critical Care Medicine, Tongji Hospital and Key Laboratory of Pulmonary Diseases of \\ Health Ministry, Tongji Medical College, Huazhong University of Science and Technology, Wuhan, PR China
}

\section{Key Words}

Asthma $\cdot$ CC chemokine ligand $2 \cdot$ Tc17 cells $\cdot$ Th17 cells .

Airway inflammation

\begin{abstract}
Background: Interleukin (IL)-17 has been implicated in the pathogenesis of asthma and the progression of airway inflammation. Here, we used a model of allergic asthma and found that the frequencies of IL-17-secreting Thelper (Th)17 and CD8 (Tc) 17 cells were both significantly increased, as was the expression of the CC chemokine receptor (CCR2) on the surface of these cells. CC chemokine ligand 2 (CCL2) has been shown to mediate the activation and recruitment of inflammatory cells in asthma, which are also skewed after ovalbumin (OVA) challenge. However, the role of CCL2 on Th17 cells and Tc17 cells in asthma has not been illuminated. Methods: Mice that were sensitized and challenged with OVA received anti-CCL2 antibody (Ab; $5 \mu \mathrm{g} /$ day intratracheally) or CCR2 antagonist (RS504393, 2 mg/kg/day intraperitoneally) prior to the challenge. Some mice received an isotype control $\mathrm{Ab}$ or vehicle alone. We then assessed the effects of allergic asthma and anti-CCL2 Ab or CCR2 antagonist treatment on the levels of IL-17 and CCL2, the Th17 and TC17 cell frequencies and lung tissue inflammation. Results: We demonstrated that CCL2 and IL-17 levels and the frequency
\end{abstract}

of Th17 and Tc17 cells in lung tissues and bronchoalveolar lavage fluid increased in the asthma group compared with the normal control mice. Blocking the CCL2/CCR2 axis greatly reduced the Th17 but not the Tc17 cell frequency, and revealed a suppressive effect on airway inflammation. Conclusion: These findings indicate a role for the CCL2/CCR2 axis in mediating Th17 but not Tc17 cell migration during acute allergic airway inflammation.

(c) 2015 S. Karger AG, Basel

\section{Introduction}

Allergic asthma is a chronic inflammatory disease that is characterized by airway hyperreactivity, limited reversible airflow and airway inflammation. Many cell types are involved in its pathogenesis, including eosinophils, $\mathrm{T}$ cells, neutrophils, mast cells and dendritic cells as well as various inflammatory mediators. Numerous clinical and experimental observations have suggested that asthma is a heterogeneous disease which includes complexities that extend beyond the T helper type 2 (Th2) cell paradigms of increased secretion of interleukin (IL)-4, IL-5, IL-9 and IL-13. These observations also revealed that non-Th2-associated factors, such as IL-17, are frequently detected in the lungs of patients with asthma. These factors can de-

\section{KARGER 125}

(c) 2015 S. Karger AG, Base

$1018-2438 / 15 / 1661-0052 \$ 39.50 / 0$

E-Mail karger@karger.com

www.karger.com/iaa
Correspondence to: Prof. Weining Xiong

Department of Respiratory and Critical Care Medicine, Tongji Hospital and Key Laboratory of Pulmonary Diseases of Health Ministry, Tongji Medical College Huazhong University of Science and Technology, 1095 Jiefang Dadao Road

Wuhan 430030 (PR China), E-Mail xiongweining@ tjh.tjmu.edu.cn 
velop independently and mediate complex heterologous interactions in allergic asthma [1].

CCL2, also known as monocyte chemotactic protein (MCP-1), is a member of the CC family of chemokines [2] that can be secreted by many cell types, including macrophages, lymphocytes, basophils, epithelial cells, airway smooth-muscle cells and neutrophils [3-8]. Accumulating evidence [9-12] indicates that CCL2 plays an important role in asthma. Asthma patients have significantly higher serum CCL2 levels than normal controls in the asymptomatic phase of the disease and also during an acute asthma attack [13]. In atopic-asthma patients, high levels of CCL2 were inversely correlated with forced expiratory volume in $1 \mathrm{~s}$ and forced expiratory flow at $50 \%$ vital capacity $[14,15]$. In Schistosoma mansoni-challenged mice, CCL2 production has been found to increase significantly and be accompanied by an influx of leukocyte migration into the lung and subsequent airway hyperreactivity [16]. CCL2 mediates the activation and recruitment of inflammatory cells into the lung by binding to its specific receptor, CCR2 $[3,17]$. Some studies have explored the relationship between the CCL2/CCR2 axis and inflammatory cells. Mellado et al. [17] found that neutralization of CCR2 attenuated macrophage and eosinophil accumulation in the bronchoalveolar lavage fluid (BALF) of asthmatic monkeys. Lukacs et al. [16] reported that neutralization of CCL2 significantly reduced total leukocyte migration, especially CD4+ and CD8+ lymphocytes, although it was not clear which T-cell subsets were involved.

Th17 cells, a proinflammatory subset of CD4+ T cells, were named for their production of IL-17. They have been shown to play a vital role in asthma by enhancing Th2-mediated eosinophilic airway inflammation and inducing neutrophil recruitment and airway hyperreactivity in Th17 cell-dependent neutrophilia [18-21]. Similar to Th17 cells, CD8+ T cells can differentiate into noncytotoxic, IL-17-producing cells in the presence of TGF- $\beta$ and IL- 6 in mixed lymphocyte cultures; they are categorized as the $\mathrm{T}$ noncytotoxic 17 (Tc17) cell subset [22]. Tc17 cells are another source of IL-17 and have been studied in asthma [23]. However, the precise role of CCL2 in Th17-cell-mediated or Tc17cell-mediated inflammation in asthma has not been described. In this study, we found a direct association between increased CCL2 levels and Th17 cell recruitment to inflammatory sites in a murine asthma model. We found that CCL2 levels in the BALF and CCR2+ Th17 cell numbers in the lung were significantly increased. IL-17 levels and Th17 cell frequencies were reduced when mice were treated with anti-CCL2 antibody ( $\mathrm{Ab}$ ) or a specific antagonist for CCR2. Furthermore, inflammatory cell infiltration in peribronchial and perivascular tissues was also diminished. However, after blockade of the CCL2/CCR2 pathway, we found no change in the percentage of Tc17 cells.

\section{Materials and Methods}

Mice

Female BALB/c mice (age: 6-8 weeks; weight: 16-22 g) were purchased from the Animal Experimental Center of Hubei Province. All mice were housed in specific pathogen-free-grade conditions at the Centers for Disease Control and Prevention of Hubei Province (animal certificate No. H20110338). All experiments conducted in this study were in accordance with the Animal Care and Use Committee of the Tongji Medical College, Huazhong University of Science and Technology.

\section{Induction of Airway Inflammation and Administration of} CCL2 Neutralizing Antibody or CCR2 Antagonist

The asthma model was constructed as before with minor modifications [24]. Briefly, mice were sensitized with $100 \mu$ g ovalbumin (OVA; grade V, Sigma-Aldrich, St. Louis, Mo., USA) conjugated with $100 \mu$ aluminum hydroxide by intraperitoneal injection on days 0,7 and 14. After 10 days, the mice were anesthetized with $10 \mathrm{mg} / \mathrm{ml}$ ketamine and $1 \mathrm{mg} / \mathrm{ml}$ xylazine diluted in sterile phosphate-buffered saline (PBS), and were then challenged with $200 \mu \mathrm{g}$ OVA or PBS $(5 \mu \mathrm{g} / \mu \mathrm{l}$, dissolved in normal saline) intratracheally every other day for 3 consecutive doses. Some mice received antiCCL2 Ab (R\&D Systems Inc., Minneapolis, Minn., USA) or isotype control rat IgG2b Ab ( $5 \mu \mathrm{g} /$ mouse; R\&D Systems) dissolved in PBS by intratracheal injection $1 \mathrm{~h}$ before challenge, as previously reported $[25,26]$. For CCR2 receptor blocking, some mice received $2 \mathrm{mg} / \mathrm{kg}$ RS504393 (Tocris Bioscience, Ellisville, Mo., USA), a selective chemical antagonist of CCR2 [27] or a DMSO vehicle control by intraperitoneal injection prior to the challenge (fig. 1a).

\section{BALF Analysis}

BALF samples were obtained as before [28]. Mouse lungs were flushed via the trachea cannula with $0.8 \mathrm{ml}$ PBS 3 times following the final OVA challenge. BALF was centrifuged at $200 \mathrm{~g}$ for $5 \mathrm{~min}$. Supernatants were stored at $-80^{\circ} \mathrm{C}$ for subsequent cytokine measurements. The total cell suspension was resuspended in $1 \mathrm{ml}$ PBS. Cells were counted using a hemocytometer. Differential cell counts were carried out after Diff-Quick staining.

\section{Lung Homogenate Preparation and Inflammatory Mediator} Measurements

Lung tissue suspensions were generated as before [29]. In brief, the right lung was dissected, then quickly frozen in liquid nitrogen and stored at $-80^{\circ} \mathrm{C}$. After thawing, lung tissues were homogenized in PBS and centrifuged at $1,000 \mathrm{~g}$ for $15 \mathrm{~min}$ at $4^{\circ} \mathrm{C}$ to remove sediment; supernatants were then harvested for the measurement of IL-17 levels. Levels of CCL2 in the BALF and IL-17 


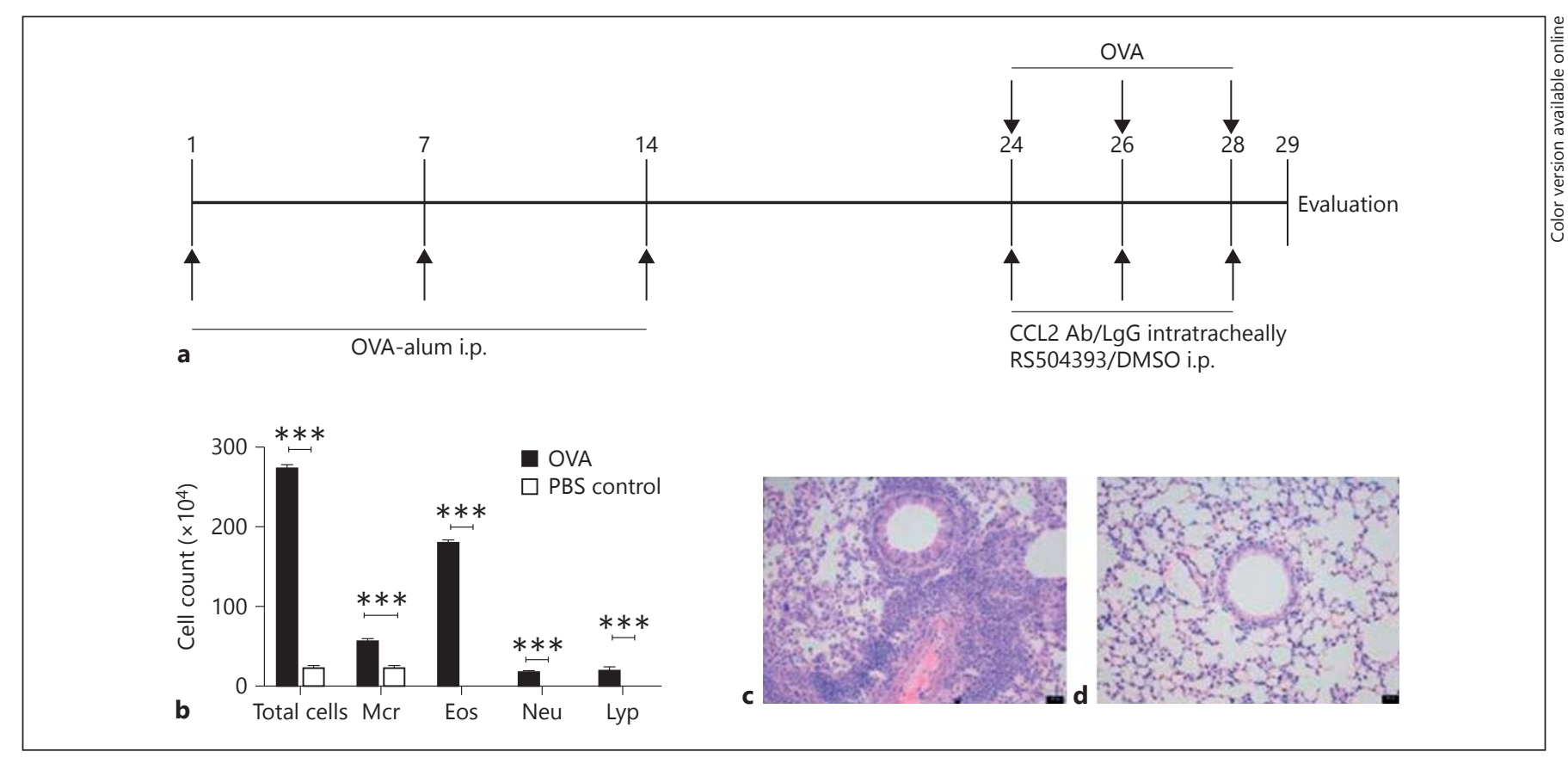

Fig. 1. OVA-induced airway inflammation in BALB/c mice: an outline of the protocol used for our OVA-induced asthma model. Mice were sensitized 3 times by intraperitoneal injection of OVA and alum on days 1, 7 and 14, followed by challenge with OVA solution (intratracheal) on days 24, 26 and 28. For some experiments, before each provocation, mice were treated with CCL2 Ab, isotype control Ab, RS504393 or DMSO vehicle control. a Airway

in lung tissue homogenates were determined using ELISA kits (Neobioscience, Beijing, PR China) according to the manufacturer's instructions.

\section{Lung Morphology and Immunofluorescence}

Lung morphology examinations were performed as before [30]. Left lobes were filled with $4 \%$ paraformaldehyde and embedded in paraffin. Next, $5 \mu \mathrm{m}$-thick longitudinal sections were deparaffinized and stained with hematoxylin and eosin (HE). The severity of peribronchial inflammation was graded semiquantitatively as before [31]. The distribution of Th17 and Tc17 cells around bronchioles and peribronchial vessels was analyzed by immunofluorescence, as previously described [32].

\section{Flow Cytometric Analysis of IL-17 and Chemokine Receptor} Expression

BALF cells and lung tissues were stimulated with phorbol ester (50 ng/ml; Sigma) and ionomycin $(1,000 \mathrm{ng} / \mathrm{ml}$; Sigma) for $5 \mathrm{~h}$. Brefeldin A (50 ng/ml; Sigma) was used to block cytokine secretion. Next, the cells were incubated with an appropriate concentration of PE-Cy5-conjugated anti-CD3 mAb and FITC-conjugated anti-CD $8 \mathrm{mAb}$ (both from Biolegend, San Diego, Calif., USA) for $30 \mathrm{~min}$ at $4^{\circ} \mathrm{C}$ in the dark. For CCR2 staining, APC-conjugated $\mathrm{mAb}$ was added to some samples. Cells were then fixed and permeabilized with cytofix/cytoperm solution (BD Biosciences, San Jose, Calif., USA) for intracellular cytokine IL-17A staining. Flow inflammation was evaluated $24 \mathrm{~h}$ after the final OVA exposure. b The number of total cells, macrophages (Mcr), eosinophils (Eos), neutrophils (Neu) and lymphocytes (Lyp) in the BALF from OVAchallenged and control mice. c, d Lung tissue sections from OVAchallenged and control mice. HE. $\times 100$. Scale bars: $50 \mu \mathrm{m}$. ${ }^{* * *} \mathrm{p}<$ 0.0001 , compared with the respective control group by unpaired $t$ test. Data indicate the means \pm SEM for groups of 4-6 mice.

cytometry was performed on a BD LSR-II cytometer to quantify the frequencies of CCR2+ Th17 cells or Tc17 cells against the totals of these cells, respectively.

\section{Statistical Analysis}

The mean and SEM were calculated for each parameter measured in this study. Statistical significance between groups was tested by one-way ANOVA using the Newman-Keuls analysis for multiple-group comparisons and the unpaired Student $t$ test for comparisons between 2 groups. We used a threshold for statistically significant differences of $\mathrm{p}<0.05$. Data were plotted and analyzed using Prism5 (GraphPad, La Jolla, Calif., USA).

\section{Results}

\section{Adaptive Airway Inflammation in the Lung after OVA Challenge}

Airway inflammation was evaluated. Total cell numbers, particularly of eosinophils, macrophages and lymphocytes in the BALF from OVA-challenged mice were higher than those in control mice ( $p<0.0001$; fig. 1b). Our analysis of the HE-stained lung tissues supported these observations (fig. 1c, d). 


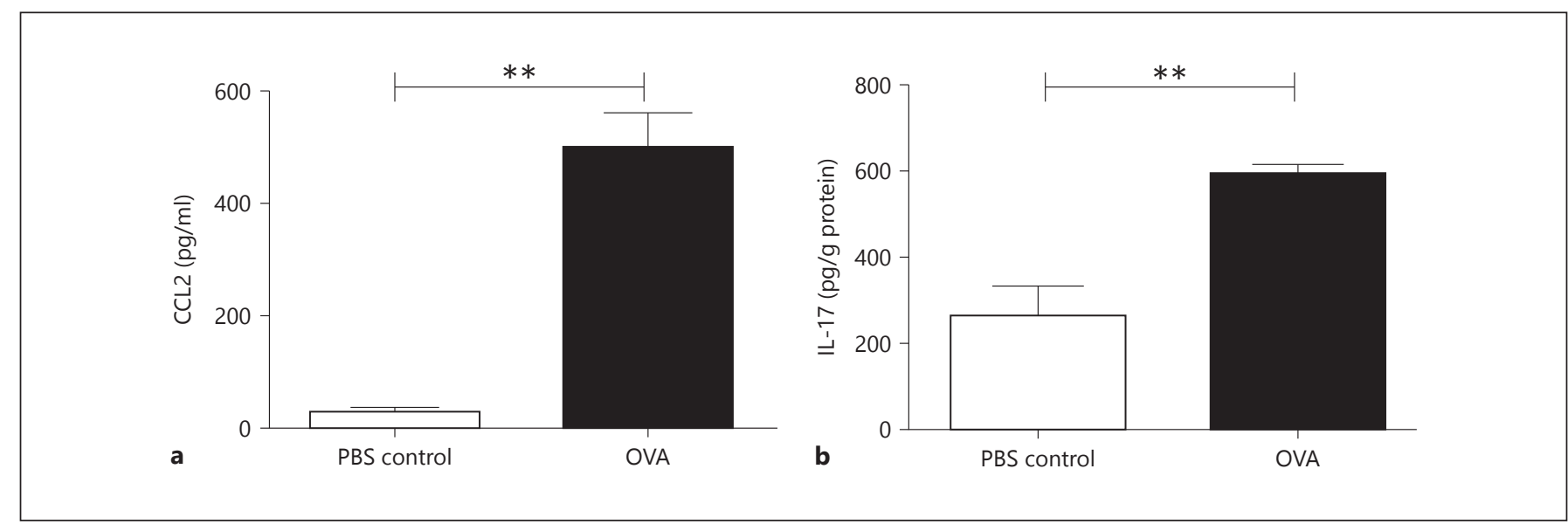

Fig. 2. a, b IL-17 levels in lung homogenates and CCL2 levels in BALF were measured by ELISA from OVA-challenged and control mice. ** $\mathrm{p}<0.01$, compared with the respective control group by unpaired $t$ test. Data shown indicate the means \pm SEM for groups of $4-6$ mice.

\section{CCL2 and IL-17 Secretion upon OVA Sensitization and Challenge}

CCL2 levels in the BALF and IL-17 levels in lung tissues were measured. We found that the concentration of CCL2 and IL-17 was significantly elevated after antigen challenge compared with the control group $(\mathrm{p}<0.01$; fig. 2a, b).

\section{Th17 and Tc17 Cell Abundance in Mice Increases after OVA Challenge}

By comparing the intracellular expression levels of IL-17 in CD4+ Th17 cells and CD8+ Tc17 cells from OVA-challenged and control mice, we found that the frequency of both Th17 cells and Tc17 cells was higher in the BALF of OVA-challenged mice $(\mathrm{p}<0.001$ and $\mathrm{p}<$ 0.01 , respectively; fig. 3a). As BALF data may not always reflect inflammatory processes that occur in the lung tissues [33], IL-17-secreting T cells in the lung tissues were further quantified by flow cytometry. We also found that the OVA-challenged mice exhibited increased Th17 and Tc17 cell frequencies $(\mathrm{p}<0.001$ and $\mathrm{p}<0.01$, respectively; fig. $3 \mathrm{~b}$ ). We also analyzed the distribution of Th17 cells and Tc17 cells in the lung, which showed increased accumulation around the bronchioles and vessels (fig. 3c).

\section{Increased Surface Expression of CCR2 on Th17 and Tc17 Cells}

To investigate the potential involvement of CCL2 in the recruitment of Th17 or Tc17 cells to the lung, we confirmed the CCR2 expression levels on the surface of the Th17 and Tc17 cells in the BALF by flow cytometry. The frequency of
CCR2+ Th17 cells against the total of Th17 cells in the OVA-challenged mice was significantly increased compared with the control mice ( $\mathrm{p}<0.05$; fig. $4 \mathrm{a})$. However, the frequency of CCR2+ Tc17 cells against total Tc17 cells was only mildly increased and this difference did not reach our threshold for statistical significance (fig. 4b).

\section{The Effect of Blocking the Inflammatory CCL2/CCR2}

Chemokine Pathway on the Recruitment of Th17 and

\section{Tc17 Cells}

There were significantly fewer Th17 cells $(\mathrm{p}<0.05)$, but not Tc17 cells ( $p>0.05)$, in the lung tissues of the mice that received anti-CCL2 Ab compared with the IgG-treated mice (fig. 5a, b), indicating a selective effect of CCL2 on the recruitment of Th17 cells. Compared with the DMSO-treated mice, the recruitment of Th17 cells, but not Tc17 cells, into the lung was significantly reduced after RS504393 administration ( $\mathrm{p}<0.01$ and not significant, respectively; fig. 5a, b). In addition, consistent with the reduced frequency of IL-17-secreting Th17 cells in the lung tissue detected by flow cytometry, fewer CD4+ and IL-17+ cells were detected by immunofluorescence in the lung tissues from the mice treated with anti-CCL2 Ab and RS504393 (fig. 5c). By contrast, we observed only minor changes in the infiltration of Tc17 cells to inflammatory sites (fig. 5d).

\section{The Effect of Blocking the Inflammatory CCL2/CCR2}

Chemokine Pathway on IL-17 and CCL2 Secretion

Next, we measured IL-17 levels in lung homogenates (we also measured IL-17 levels in BALF, but detected very low levels) and CCL2 levels in the BALF. Compared 

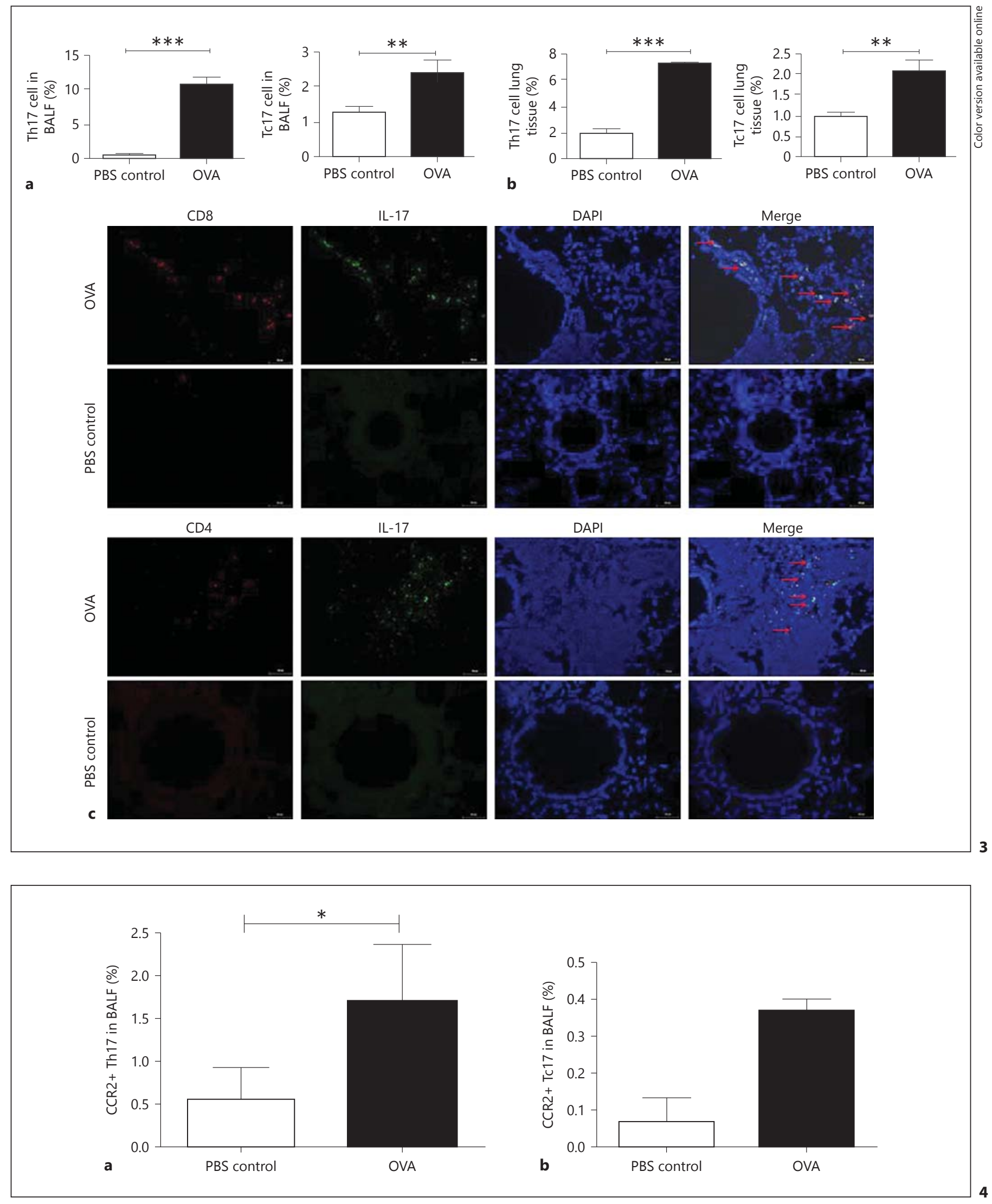

(For legends 3 and 4 see next page.) 

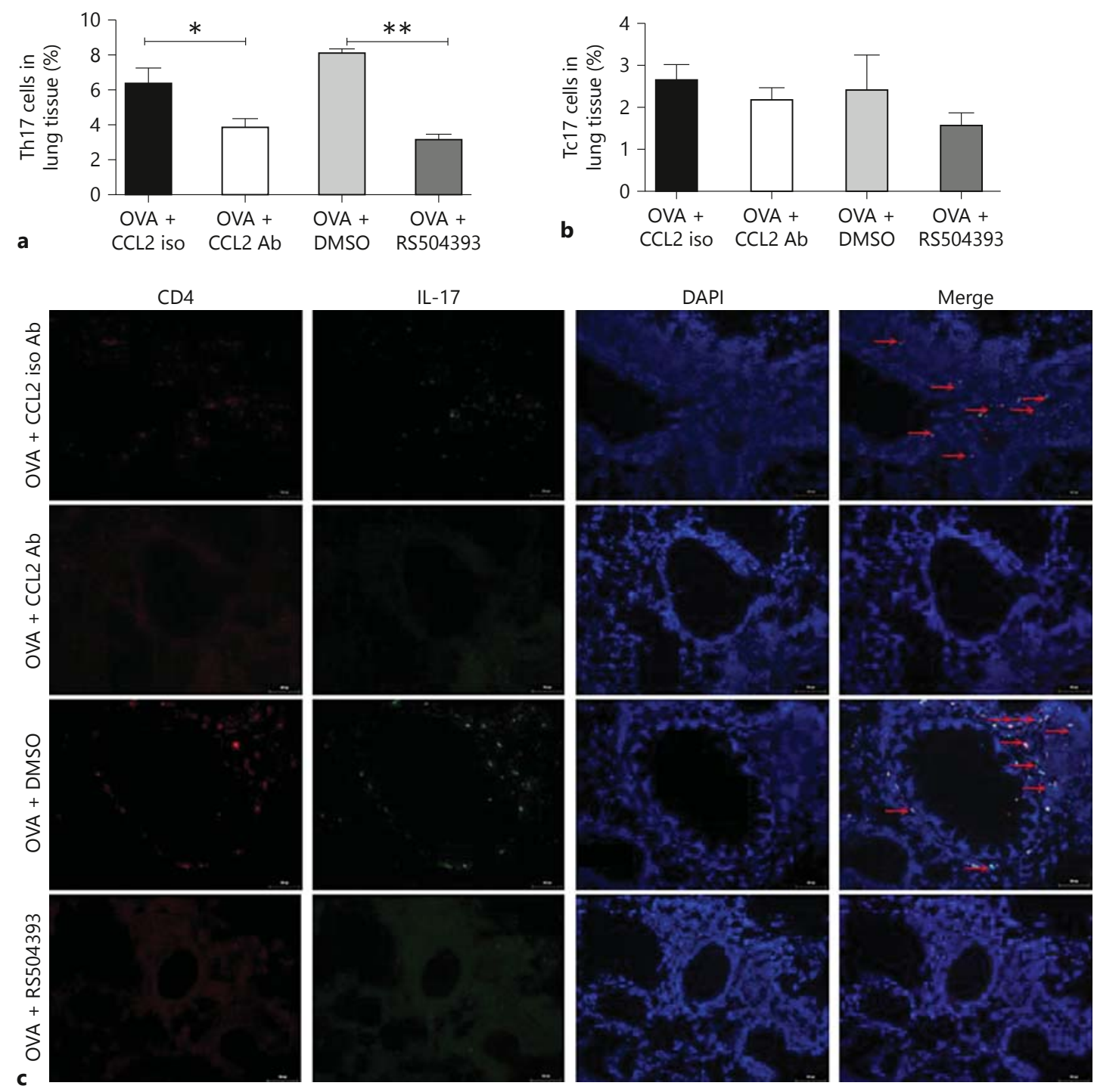

Fig. 5. a, b Blockade of the CCL2/CCR2 pathway significantly reduces the recruitment of allergen-specific Th17 but not Tc17 cells to the lung. Th17 and Tc17 cell frequencies in lung tissues from isotype control Ab-, CCL2 Ab-, DMSO- or RS504393-treated mice. c, d Colocalization of CD4 or CD8 with IL-17A in the lungs

Fig. 3. a, b Th17 and Tc17 cell frequencies increased during the development of allergen-specific adaptive responses. Data for Th17 and Tc17 cell frequencies in BALF and lung tissues from OVA-challenged and control mice were measured by flow cytometry. c Colocalization of CD4 or CD8 with IL-17A in the

Fig. 4. a, b Increased CCR 2 expression on the surface of Th17 and Tc17 cells. Bars indicate the frequencies of CCR $2+$ Th17 cells and CCR2+ Tc17 cells against the total Th17 cells or total Tc17 cells, respectively, in BALF from OVA-challenged and control of isotype control Ab- (iso Ab), CCL2 Ab-, DMSO- or RS504393treated mice. Th17 and Tc17 cells (arrows) were visualized. $\times 200$. Scale bars: $50 \mu \mathrm{m}$. ${ }^{* *} \mathrm{p}<0.01,{ }^{*} \mathrm{p}<0.05$, as compared among the indicated groups by one-way ANOVA. Data indicate the means \pm SEM for groups of 4-6 mice. iso $\mathrm{Ab}=$ Isotype control Ab.

(For figure $5 d$ see next page.)

lungs of OVA-challenged and control mice; Th17 and Tc17 cells (arrows) were visualized. $\times 200$. Scale bars: $50 \mu \mathrm{m} .{ }^{* * *} \mathrm{p}<0.001$, $* * \mathrm{p}<0.01$, compared with the respective control group by unpaired $t$ test. Data indicate the means \pm SEM for groups of 4-6 mice.

mice, as quantified by flow cytometry. ${ }^{*} \mathrm{p}<0.05$, compared with the respective control group by unpaired t test. Data indicate the means \pm SEM for groups of 4-6 mice. 


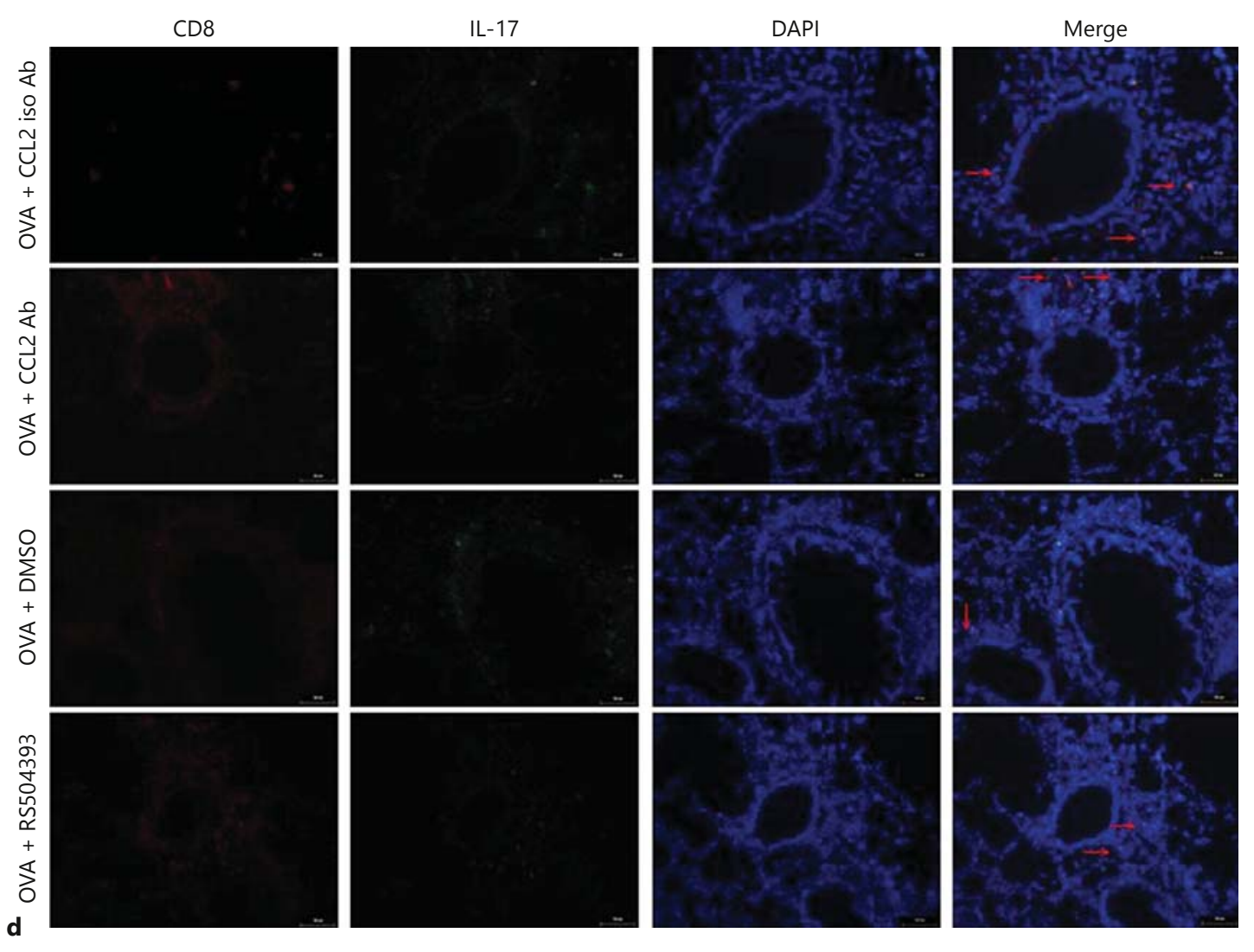

with IgG-treated mice, mice that received anti-CCL2 Ab showed a significant reduction in IL-17 levels $(\mathrm{p}<0.01)$. In contrast to DMSO-treated mice, IL-17 levels were also moderately reduced in the RS504393-treated mice, but the difference was not statistically significant (fig. 6a). Notably, reduced CCL2 levels were also detected after RS504393-treatment when compared with DMSO-treated vehicle control mice ( $p<0.01$; fig. $6 b)$.

The Effect of Blocking the Inflammatory CCL2/CCR2 Chemokine Pathway on Airway Inflammation

After the final challenge, lung pathology and BALF cellularity were assessed. Compared with the mice treated with isotype control $\mathrm{Ab}$ or DMSO, the mice that received anti-CCL2 Ab or RS504393 exhibited alleviated inflammation in both the peribronchial and perivascular areas of the lung, indicated by both HE staining and semiquantitative inflammatory scoring $(\mathrm{p}<0.01$; fig. $7 \mathrm{a}-\mathrm{d})$. Furthermore, the total of inflammatory cells and BALF eosinophils was significantly reduced in both the anti-CCL2
Ab-treated and RS504393-treated groups ( $<<0.05)$. A significant reduction in lymphocyte numbers was observed in the RS504393-treated mice $(\mathrm{p}<0.001)$ and a moderate reduction in macrophage and neutrophil numbers, though the differences were not significant (fig. 7e).

\section{Discussion}

In this study, we established an asthmatic model that resulted in increased eosinophil and Th17 cell infiltration to the lung, accompanied by increased levels of CCL 2 and IL-17. We showed that Th17 and Tc17 cells accumulated in the lung, and that CCR2 expression levels also increased on the surface of these cells. The CCL2/CCR2 chemokine pathway can promote $\mathrm{Th} 17$ cell recruitment to the lung in vivo, but may have no effect on Tc17 cell recruitment.

CCL2, which was initially identified as a monocyte chemotactic protein, is also a potent chemoattractant for macrophages, mast cells and eosinophils via their CCR2
Wang/Wang/Cao/Cheng/Chen/Bunjhoo/ $\mathrm{Xie} / \mathrm{Wang} / \mathrm{Xu} / \mathrm{Xiong}$ 

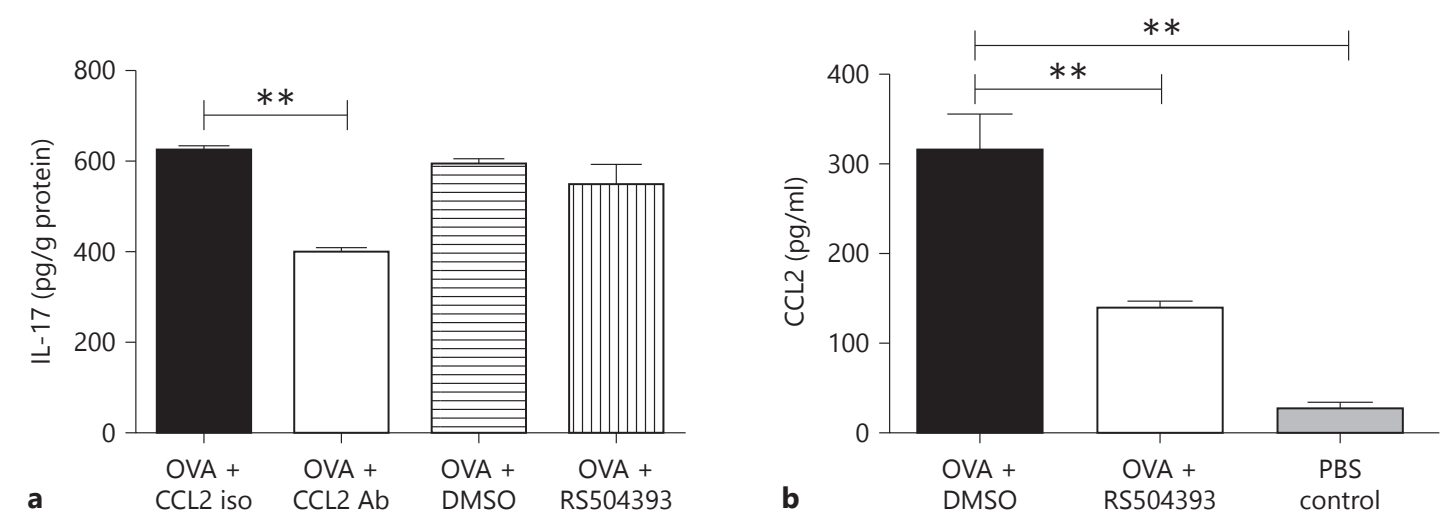

Fig. 6. a, b Cytokine secretion declined after blockade of the inflammatory CCL2/CCR2 chemokine pathway. IL-17 production in lung homogenates and CCL2 levels in BALF were measured by ELISA.

** $\mathrm{p}<0.01$, as compared among the indicated groups by one-way ANOVA. Data indicate the means \pm SEM for groups of 4-6 mice. iso $=$ Isotype.

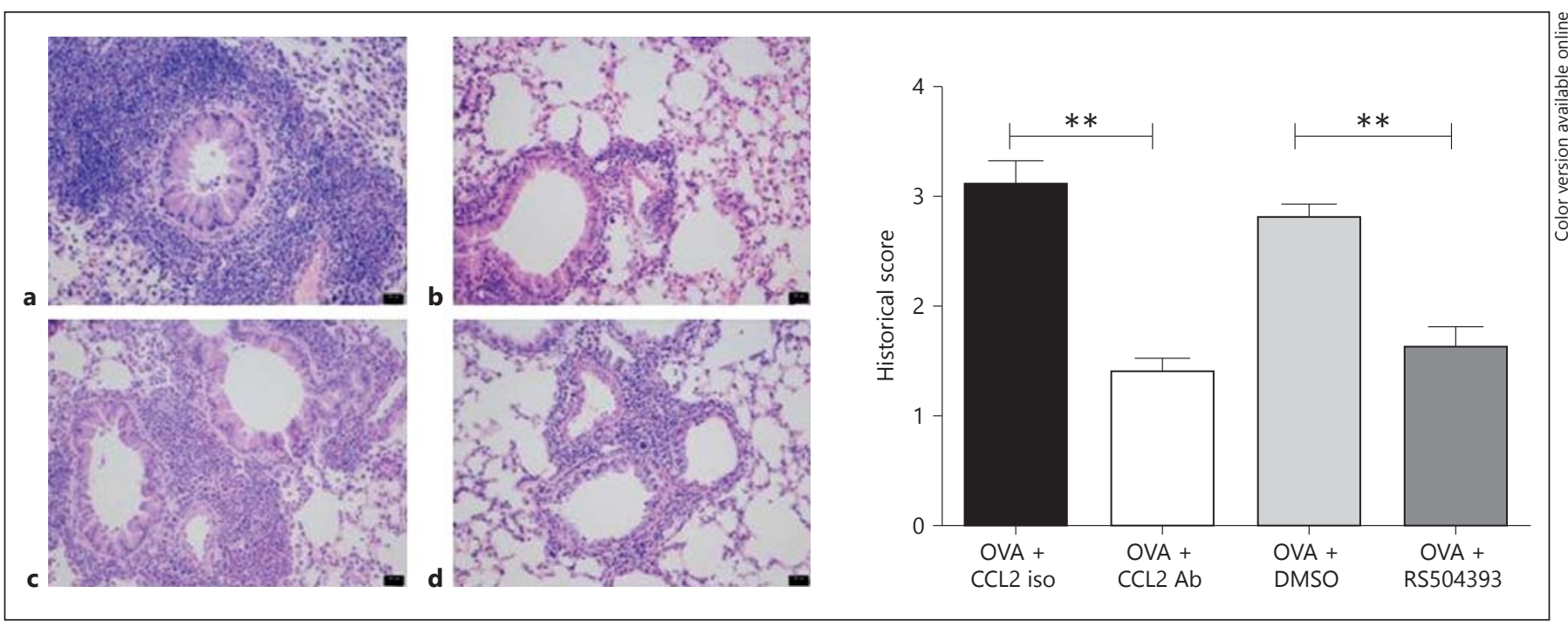

Fig. 7. Development of airway inflammation was significantly alleviated after CCL2/CCR2 pathway blockade. HE-stained lungs from isotype (iso) control Ab- (a), CCL2 Ab- (b), DMSO- (c) or RS504393-treated mice (d) $24 \mathrm{~h}$ after the final challenge with OVA. HE. On the right, quantification of the histological images is shown. Images were scored by at least two pathologists and the mean score was used as the inflammation index, which represents the severity of peribronchial inflammation. e The number of total cells, macrophages (Mcr), eosinophils (Eos), neutrophils (Neu) and lymphocytes (Lyp) in the BALF $24 \mathrm{~h}$ after the final challenge with OVA. ${ }^{* * *} \mathrm{p}<0.001,{ }^{* *} \mathrm{p}<0.01,{ }^{*} \mathrm{p}<0.05$, compared with the respective control group by unpaired test. Data shown indicate the means \pm SEM for groups of 4-6 mice.

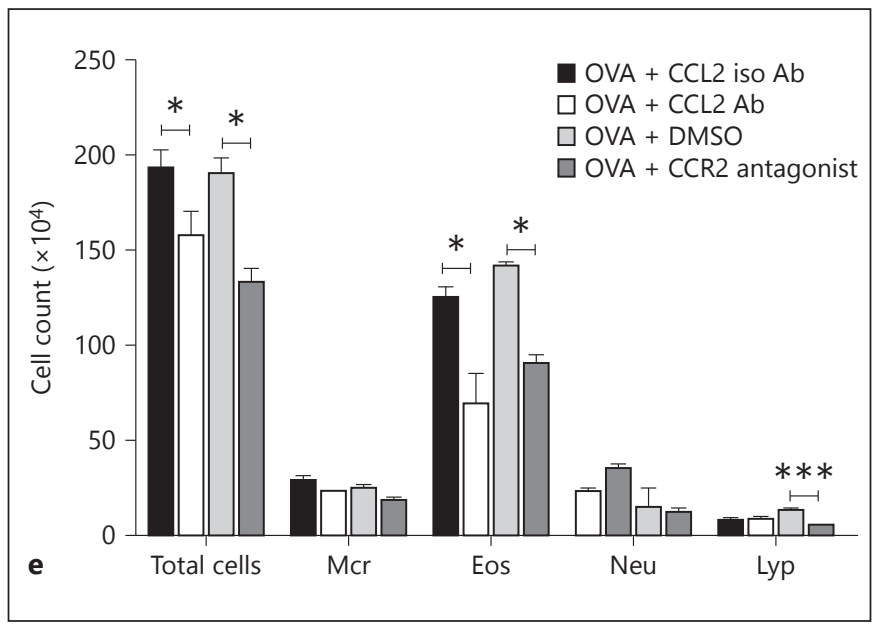


[34-36]. In research on the pathogenesis of asthma, Mellado et al. [17] found that the neutralization of CCR2 attenuated macrophage and eosinophil accumulation in the BALF of asthmatic monkeys. Our study also found that the number of eosinophils and lymphocytes was reduced after the treatment with anti-CCL2 Ab or CCR2 antagonist, and although the differences were not significant, a moderate reduction in macrophage numbers was also observed. This supports the finding by Mellado et al. [17]. Lukacs et al. [16] reported that neutralization of CCL2 significantly reduced total leukocyte migration, especially of CD4+ and CD8+ lymphocytes; our study also found a significant reduction in lymphocyte numbers in the RS504393-treated mice. The elevated levels of CCL2 and the increased numbers of lymphocytes in BALF were observed in OVA-challenged animals and were significantly reduced when the mice were treated with CCR2 antagonist, leading to the assumption that, in asthma, a large portion of CCL2 is released from lymphocytes.

On flow cytometry, we detected a significant increase in the frequency of Th17 and Tc17 cells that migrated to the BALF and lung tissue. The location of both the Th17 and Tc17 cells in the lung was characterized by a peribronchial and perivascular distribution visible by immunofluorescence. These data suggest that the accumulation of both IL-17-secreting Th17 and Tc17 cells in the lung represents one of the drivers of immunopathology following OVA stimulation.

Th17 cells are known to express the chemokine receptor CCR2 in vitro [37]. The CCL2/CCR2 axis is relevant in various autoimmune diseases, such as multiple sclerosis, autoimmune encephalomyelitis and autoimmune arthritis [38-40]. However, the role of the CCL2/CCR2 axis in the migration of Th17 and Tc17 cells to the lung in allergic asthma has not yet been reported. We thus investigated the expression of CCR2 on Th17 and Tc17 cells in asthmatic mice and found that the frequency of CCR2 expression in both cell subsets was increased. Using anti-CCL2 Ab for CCL2 neutralization or RS504393 for CCR2 blockade in vivo, in both treatments, we observed a significant reduction in the frequency of Th17 cells and a change in their distribution, compared with mice treated with isotype control Ab and DMSO, on flow cytometry and by immunofluorescence. This result was accompanied by a reduction in the IL-17 expression and in lung inflammation. All of these findings indicated that the CCL2/CCR2 interaction plays an important role in the OVA-induced migration of Th17 cells and airway inflammation. Taken together, treatment with anti-CCL2 or CCR2 antagonist reduced lung inflammation which was due, at least in part, to the reduced infiltration of Th17 cells.

In addition, for the first time, we emphasized the role of CCL2 on the migration of Th17 and Tc17 cells to the lung and the subsequent effects on airway inflammation. However, compared with the mice treated with isotype control Ab or DMSO, the reduction of Tc17 cells was not as remarkable as the effect on the Th17 cells that we observed in both the CCL2 Ab-treated and RS534393-treated mice, suggesting that the CCL2/CCR2 cytokine signaling pathway might be not essential for Tc17 cell recruitment during inflammation. A previous study of inflamed liver tissue suggested that Tc17 cells express high levels of CXCR3, CCR6 and CXCR6, and that the increasing expression of CXCR3 mediates Tc17 cells recruitment [41]. The small amount of Tc17 cells and difficulty in their detection might be another reason for the discordant results. Thus, characterizing the precise mechanisms used for Tc17 cell recruitment to inflammatory sites will require further research.

The elevated levels of CCL2 and IL-17 in BALF and lung homogenates were observed in OVA-challenged animals. After CCR2 blockade, CCL2 levels also showed a significant reduction in BALF that paralleled the reduced IL-17 levels. This finding may imply that a regulatory loop exists between CCL2 and Th17 cells. The potential mechanisms involved, shown in vitro by Wong et al. [42], include the IL-17-dependent enhancement of ICAM-1 expression on the surface of primary bronchial epithelial cells and BEAS-2B cells via intracellular signaling events that result in the activation of NF- $\kappa B$ and p38 MAPK. Subsequently, ICAM-1/CD18 interactions between bronchial epithelial cells and basophils induce the activation of ERK, p38 MAPK, JNK and $\mathrm{NF}-\kappa \mathrm{B}$, which might provide sufficient stimulation to cause the release of CCL2. Thus, cross-talk between CCL2 and IL-17 in allergic asthma might play an important role in perpetuating pulmonary inflammation.

In summary, we provide compelling evidence for a direct association between CCL2 and Th17 cells in vivo. This study provides new insights into our understanding of the role of the CCL2/CCR2 pathway in asthma through the recruitment Th17 cells to the lung. This may aid the development of novel asthma treatment strategies.

\section{Acknowledgment}

This work was supported by the National Natural Science Foundation of China (Nos. 81170021 and 30900647).
Wang/Wang/Cao/Cheng/Chen/Bunjhoo/ Xie/Wang/Xu/Xiong 


\section{References}

1 Cua DJ, Tato CM: Innate IL-17-producing cells: the sentinels of the immune system. Nat Rev Immunol 2010;10:479-489.

2 Page SH, Wright EK Jr, Gama L, Clements JE: Regulation of CCL2 expression by an upstream tale homeodomain protein-binding site that synergizes with the site created by the A-2578G SNP. PLoS One 2011;6:e22052.

3 Schneider D, Hong JY, Bowman ER, Chung Y, Nagarkar DR, McHenry CL, Goldsmith AM, Bentley JK, Lewis TC, Hershenson MB: Macrophage/epithelial cell CCL2 contributes to rhinovirus-induced hyperresponsiveness and inflammation in a mouse model of allergic airways disease. Am J Physiol Lung Cell Mol Physiol 2013;304:L162-L169.

4 Leonard EJ, Skeel A, Yoshimura T: Biological aspects of monocyte chemoattractant protein-1 (MCP-1). Adv Exp Med Biol 1991;305: 57-64.

5 Sironi M, Munoz C, Pollicino T, Siboni A, Sciacca FL, Bernasconi S, Vecchi A, Colotta F, Mantovani A: Divergent effects of interleukin-10 on cytokine production by mononuclear phagocytes and endothelial cells. Eur J Immunol 1993;23:2692-2695.

6 Holgate ST, Bodey KS, Janezic A, Frew AJ, Kaplan AP, Teran LM: Release of RANTES, MIP-1 alpha, and MCP-1 into asthmatic airways following endobronchial allergen challenge. Am J Respir Crit Care Med 1997;156: 1377-1383.

7 Patel JK, Clifford RL, Deacon K, Knox AJ: Ciclesonide inhibits TNFalpha- and IL-1betainduced monocyte chemotactic protein-1 (MCP-1/CCL2) secretion from human airway smooth muscle cells. Am J Physiol Lung Cell Mol Physiol 2012;302:L785-L792.

8 Pelletier M, Maggi L, Micheletti A, Lazzeri E, Tamassia N, Costantini C, Cosmi L, Lunardi C, Annunziato F, Romagnani S, Cassatella MA: Evidence for a cross-talk between human neutrophils and Th17 cells. Blood 2010;115: 335-343.

9 Radman M, Hassanshahi G, Vazirinejad R, Arababadi MK, Karimabad MN, Khorramdelazad H, Rafatpanah H, Iranmanesh F, Hakimizadeh E, Ahmadi Z: Serum levels of the CC chemokines CCL2, CCL5, and CCL11 in food allergic children with different clinical manifestations. Inflammation 2013;36:561566.

10 Chelbi H, Ghadiri A, Lacheb J, Ghandil P, Hamzaoui K, Hamzaoui A, Combadiere C: A polymorphism in the CCL2 chemokine gene is associated with asthma risk: a case-control and a family study in Tunisia. Genes Immun 2008;9:575-581.

11 Rose CE Jr, Sung SS, Fu SM: Significant involvement of CCL2 (MCP-1) in inflammatory disorders of the lung. Microcirculation 2003; 10:273-288.

12 Kato M, Yamada Y, Maruyama K, Hayashi Y: Serum eosinophil cationic protein and $27 \mathrm{cy}$ tokines/chemokines in acute exacerbation of childhood asthma. Int Arch Allergy Immunol 2010;152(suppl 1):62-66.

13 Chan CK, Kuo ML, Yeh KW, Ou LS, Chen LC, Yao TC, Huang JL: Sequential evaluation of serum monocyte chemotactic protein 1 among asymptomatic state and acute exacerbation and remission of asthma in children. J Asthma 2009;46:225-228.

14 Jahnz-Rozyk KM, Kuna P, Pirozynska E: Monocyte chemotactic and activating factor/ monocyte chemoattractant protein (MCAF/ MCP-1) in bronchoalveolar lavage fluid from patients with atopic asthma and chronic bronchitis. J Investig Allergol Clin Immunol 1997;7:254-259.

15 Alam R, York J, Boyars M, Stafford S, Grant JA, Lee J, Forsythe P, Sim T, Ida N: Increased MCP-1, RANTES, and MIP-1alpha in bronchoalveolar lavage fluid of allergic asthmatic patients. Am J Respir Crit Care Med 1996; 153:1398-1404.

16 Lukacs NW, Strieter RM, Warmington K, Lincoln P, Chensue SW, Kunkel SL: Differential recruitment of leukocyte populations and alteration of airway hyperreactivity by $\mathrm{C}-\mathrm{C}$ family chemokines in allergic airway inflammation. J Immunol 1997;158:4398-4404.

17 Mellado M, Martin de Ana A, Gomez L, Martinez C, Rodriguez-Frade JM: Chemokine receptor 2 blockade prevents asthma in a cynomolgus monkey model. J Pharmacol Exp Ther 2008;324:769-775.

18 Wakashin H, Hirose K, Maezawa Y, Kagami S, Suto A, Watanabe N, Saito Y, Hatano M, Tokuhisa T, Iwakura Y, Puccetti P, Iwamoto I, Nakajima H: IL-23 and Th17 cells enhance Th2-cell-mediated eosinophilic airway inflammation in mice. Am J Respir Crit Care Med 2008;178:1023-1032.

19 Wilson RH, Whitehead GS, Nakano H, Free ME, Kolls JK, Cook DN: Allergic sensitization through the airway primes Th17-dependent neutrophilia and airway hyperresponsiveness. Am J Respir Crit Care Med 2009;180: 720-730.

20 Nakagome K, Matsushita S, Nagata M: Neutrophilic inflammation in severe asthma. Int Arch Allergy Immunol 2012;158(suppl 1):96102.

21 Naji N, Smith SG, Gauvreau GM, O’Byrne PM: T helper 17 cells and related cytokines after allergen inhalation challenge in allergic asthmatics. Int Arch Allergy Immunol 2014; 165:27-34.

22 Liu SJ, Tsai JP, Shen CR, Sher YP, Hsieh CL, Yeh YC, Chou AH, Chang SR, Hsiao KN, Yu FW, Chen HW: Induction of a distinct CD8 Tnc17 subset by transforming growth factorbeta and interleukin-6. J Leukoc Biol 2007;82: 354-360.

23 Reber LL, Daubeuf F, Plantinga M, De Cauwer L, Gerlo S, Waelput W, Van Calenbergh S, Tavernier J, Haegeman G, Lambrecht BN, Frossard N, De Bosscher K: A dissociated glucocorticoid receptor modulator reduces air- way hyperresponsiveness and inflammation in a mouse model of asthma. J Immunol 2012; 188:3478-3487.

24 Rangasamy T, Guo J, Mitzner WA, Roman J, Singh A, Fryer AD, Yamamoto M, Kensler TW, Tuder RM, Georas SN, Biswal S: Disruption of Nrf2 enhances susceptibility to severe airway inflammation and asthma in mice. J Exp Med 2005;202:47-59.

25 Penido C, Costa MF, Souza MC, Costa KA, Candea AL, Benjamim CF, Henriques $\mathrm{M}$ : Involvement of cc chemokines in gammadelta $\mathrm{T}$ lymphocyte trafficking during allergic inflammation: the role of CCL2/ CCR2 pathway. Int Immunol 2008;20:129139.

26 Gonzalo JA, Lloyd CM, Wen D, Albar JP, Wells TN, Proudfoot A, Martinez AC, Dorf M, Bjerke T, Coyle AJ, Gutierrez-Ramos JC: The coordinated action of CC chemokines in the lung orchestrates allergic inflammation and airway hyperresponsiveness. J Exp Med 1998;188:157-167.

27 Souto FO, Alves-Filho JC, Turato WM, Auxiliadora-Martins M, Basile-Filho A, Cunha FQ: Essential role of CCR2 in neutrophil tissue infiltration and multiple organ dysfunction in sepsis. Am J Respir Crit Care Med 2011;183:234-242.

28 Nakagome K, Imamura M, Okada H, Kawahata $\mathrm{K}$, Inoue $\mathrm{T}$, Hashimoto $\mathrm{K}$, Harada $\mathrm{H}$, Higashi T, Takagi R, Nakano K, Hagiwara K, Kanazawa M, Dohi M, Nagata M, Matsushita S: Dopamine D1-like receptor antagonist attenuates Th17-mediated immune response and ovalbumin antigen-induced neutrophilic airway inflammation. J Immunol 2011;186: 5975-5982.

29 You QH, Zhang D, Niu CC, Zhu ZM, Wang N, Yue Y, Sun GY: Expression of IL-17A and IL-17F in lipopolysaccharide-induced acute lung injury and the counteraction of anisodamine or methylprednisolone. Cytokine 2014; 66:78-86.

30 Wilder JA, Collie DD, Bice DE, Tesfaigzi Y, Lyons CR, Lipscomb MF: Ovalbumin aerosols induce airway hyperreactivity in naive DO11.10 $\mathrm{T}$ cell receptor transgenic mice without pulmonary eosinophilia or ova-specific antibody. J Leukoc Biol 2001;69:538547.

31 Price MM, Oskeritzian CA, Falanga YT, Harikumar KB, Allegood JC, Alvarez SE, Conrad D, Ryan JJ, Milstien S, Spiegel S: A specific sphingosine kinase 1 inhibitor attenuates airway hyperresponsiveness and inflammation in a mast cell-dependent murine model of allergic asthma. J Allergy Clin Immunol 2013; 131:501-511.e501.

32 Li K, Wang Z, Cao Y, Bunjhoo H, Zhu J, Chen Y, Xiong S, Xu Y, Xiong W: The study of the ratio and distribution of Th17 cells and Tc17 cells in asthmatic patients and the mouse model. Asian Pac J Allergy Immunol 2013;31: 125-131. 
33 Uller L, Persson CG, Erjefalt JS: Resolution of airway disease: removal of inflammatory cells through apoptosis, egression or both? Trends Pharmacol Sci 2006;27:461-466.

34 Sica A, Wang JM, Colotta F, Dejana E, Mantovani A, Oppenheim JJ, Larsen CG, Zachariae CO, Matsushima K: Monocyte chemotactic and activating factor gene expression induced in endothelial cells by IL-1 and tumor necrosis factor. J Immunol 1990;144:3034-3038.

35 Collington SJ, Hallgren J, Pease JE, Jones TG, Rollins BJ, Westwick J, Austen KF, Williams TJ, Gurish MF, Weller CL: The role of the CCL2/ CCR2 axis in mouse mast cell migration in vitro and in vivo. J Immunol 2010;184:6114-6123.

36 Campbell EM, Charo IF, Kunkel SL, Strieter RM, Boring L, Gosling J, Lukacs NW: Monocyte chemoattractant protein-1 mediates cockroach allergen-induced bronchial hyperreac- tivity in normal but not CCR2-/- mice: the role of mast cells. J Immunol 1999;163:2160-2167.

37 Webb A, Johnson A, Fortunato M, Platt A, Crabbe T, Christie MI, Watt GF, Ward SG, Jopling LA: Evidence for PI-3K-dependent migration of Th17-polarized cells in response to CCR2 and CCR6 agonists. J Leukoc Biol 2008;84:1202-1212.

38 Sato W, Tomita A, Ichikawa D, Lin Y, Kishida H, Miyake S, Ogawa M, Okamoto T, Murata M, Kuroiwa Y, Aranami T, Yamamura T: CCR2(+)CCR5(+) $\mathrm{T}$ cells produce matrix metalloproteinase- 9 and osteopontin in the pathogenesis of multiple sclerosis. J Immunol 2012;189:5057-5065.

39 Li H, Nourbakhsh B, Safavi F, Li K, Xu H, Cullimore M, Zhou F, Zhang G, Rostami A: Kit (W-sh) mice develop earlier and more severe experimental autoimmune encephalomyelitis due to absence of immune suppression. J Immunol 2011;187:274-282.

40 Rampersad RR, Tarrant TK, Vallanat CT, Quintero-Matthews T, Weeks MF, Esserman DA, Clark J, Di Padova F, Patel DD, Fong AM, Liu P: Enhanced Th17-cell responses render CCR2-deficient mice more susceptible for autoimmune arthritis. PLoS One 2011;6:e25833.

41 Oo YH, Banz V, Kavanagh D, Liaskou E, Withers DR, Humphreys E, Reynolds GM, Lee-Turner L, Kalia N, Hubscher SG, Klenerman P, Eksteen B, Adams DH: CXCR3-dependent recruitment and CCR6-mediated positioning of Th-17 cells in the inflamed liver. J Hepatol 2012;57:1044-1051.

42 Wong CK, Cao J, Yin YB, Lam CW: Interleukin-17A activation on bronchial epithelium and basophils: a novel inflammatory mechanism. Eur Respir J 2010;35:883-893. 